\title{
Gênero e sexualidade no lócus família/ escola: incursões deflagradas a não heterossexualidade e os desafios para a cidadania reconhecida
}

\author{
Maria de Fátima Di Gregorio' \\ Karine Nascimento Silva ${ }^{2}$
}

\section{Resumo:}

Vislumbram-se neste estudo, possibilidades de diálogo entre o tema Educação, Gênero, Diversidade Sexual e Direitos Humanos no lócus da Família e da Escola, tendo o recorte na sexualidade não heterossexual e seus desafios desde a orientação na família e a construção das identidades de gênero no cenário escolar/social. Sabe-se que nesses espaços, a violência homofóbica se materializa, legitimando condutas preconceituosas nos diversos âmbitos da sociedade. Com base em estudos bibliográficos e a partir de pesquisas realizadas em campo empírico escolas públicas do município de Jequié/BA - discute-se o tema, salientando-se a importância do refletir sobre as posturas estigmatizadoras das pessoas na família e na própria escola e a garantia dos Direitos Humanos através da criação de ações e políticas públicas promotoras de uma cultura de paz e do respeito à diversidade humana. A pesquisa mostrou que se faz necessário criar condições propícias para a emergência de novos paradigmas na família e na escola, com olhar voltado para a questão da legitimação dessas condutas preconceituosas, onde pensar a alteridade fundamenta o resgate de uma ética mais comprometida com o processo de inclusão social.

Palavras-chave: Direitos Humanos. Diversidade Sexual. Escola. Família.

\footnotetext{
1 Doutorado em Família na Sociedade Contemporânea na Universidade Católica do Salvador/UCSAL, Mestrado em Memória Social pela UNIRIO, Especialização em Planejamento e Prática de Ensino pela FEEBA, Pedagoga e Historiadora. Atualmente é Professora do Mestrado em Relações Étnicas e Contemporaneidade da Universidade Estadual do Sudoeste da Bahia - linha de pesquisa: Etnias, Gênero e Diversidade Sexual, ministrando na graduação a disciplina História da Educação Brasileira na UESB e na UNEB Campus V. e-mail: f_digregorio@hotmail.com. 2 Mestrado em Família na Sociedade Contemporânea pela UCSAL, Especialização em Gestão Escolar. Integrante do grupo de pesquisa do NPEJI sobre Juventude, gênero, sexualidade, família e escola, financiado pelo CNPq. Concentra seus estudos nas políticas educacionais em defesa da infância, estudos sobre a família, gênero, violência(s), juventudes, sexualidade(s), sexualidade(s) não heterossexuais, educação e diversidade sexual e educação para e pelos Direitos Humanos. e-mail: karinensilva@hotmail.com.
} 


\section{Gender and sexuality in the locus family/school: incursions triggered towards non-heterosexuality and the challenges concerning recognizable citizenship}

\author{
Género y sexualidad en el lócus \\ familia/escuela: incursiones \\ desencadenadas a la no \\ heterosexualidad y los desafíos para la \\ ciudadanía reconocida
}

Abstract

It is envisaged, in this study, the creation of possibilities of dialogue between the theme Education, Gender, Sexual Diversity and Human Rights in the locus of Family and School, having as its focus the non-heterosexuality and its challenges since the orientation in the family and the construction of gender identities in the school/social scene. It is known that in these spaces, homophobic violence is materialized, legitimizing prejudicial behavior in different spheres of society. Based on bibliographical and empirical research in the field - public schools of the municipality of Jequié/BA the topic is discussed, by emphasizing the importance of reflection on stigmatizing attitudes of people in the family and at school and the guarantee of Human rights, by creating actions and public policies which promote a culture of peace and respect for human diversity. Research has shown that it is necessary to create conducive conditions for the emergence of new paradigms in the family and at school, by turning our eyes to the question of the legitimacy of such prejudicial conduct, where thinking about the otherness underlies the rescue of more committed ethics in what concerns the process of social inclusion.

Keywords: Human Rights. Sexual Diversity. School. Family.

\section{Resumen}

Se vislumbra en este estudio, posibilidades del diálogo entre el tema Educación, Género, Diversidad Sexual y Derechos Humanos en el lócus de la familia y de la escuela, que tiene el recorte en la sexualidad no heterosexual y sus desafíos desde la orientación en la familia y la construcción de las identidades de género en el ámbito escolar/social. Se sabe que en esos espacios, la violencia homófoba se materializa, legitimando conductas prejuiciosas en diversos ámbitos de la sociedad. Basándose en estudios bibliográficos y a partir de investigaciones realizadas en campo empírico - escuelas públicas de la municipalidad de Jequie / BA se discute el tema, haciendo hincapié en la importancia de la reflexión sobre las actitudes estigmatizadoras de personas en la familia y en la propia escuela y la garantía de los Derechos Humanos, mediante la creación de acciones y políticas públicas de promoción de una cultura de paz y respeto por la diversidad humana. La investigación ha demostrado que es necesario crear las condiciones que favorezcan la emergencia de nuevos paradigmas en la familia y en la escuela, con los ojos clavados hacia la cuestión de la legitimación de tales conductas prejuiciosas donde pensar acerca de la alteridad fundamenta el rescate de una ética más comprometida con el proceso de la inclusión social.

Palabras clave: Derechos Humanos. Diversidad Sexual. Escuela. Familia. 


\section{Introdução}

Em tempos de ausências substanciais no convívio humano, os conceitos e os discursos sobre os Direitos Humanos fazem mais presentes nos diversos âmbitos da sociedade, trazendo inquietantes discussões sobre a sexualidade não heterossexual pelas suas amplas visões. Há necessidade de fomentar uma ressignificação, ou maior compreensão crítica entre o marco legal e a dinâmica social que envolve a questão da sexualidade não heterossexual no lócus família e escola.

O recorte apresentado no presente artigo vislumbra as possibilidades de diálogo entre o tema desde seus marcos legais, vislumbrando a questão dos Direitos Humanos e a questão da cidadania reconhecida, que traz à tona as diversas formas de violência sobre a diversidade sexual, especialmente no cotidiano desses lócus constitutivos na formação das identidades.

A primeira tentativa de diálogo está no entendimento sobre os Direitos Humanos, partindo da assertiva da declaração universal adotada e proclamada pela Resolução 217 no Art III ${ }^{1}$ que considera e reconhece a dignidade imanente a todos (as) os humanos (as) com direitos iguais e inalienáveis de liberdade, justiça e gozo da paz no viver o mundo. Sendo assim, o desrespeito e violação aos mesmos serão considerados ultrajes à consciência da humanidade como também atos bárbaros. A seguir, os artigos I e II sinalizam que:

Artigo I

Todas as pessoas nascem livres e iguais em dignidade e direitos. São dotadas de razão e consciência e devem agir em relação umas às outras com espírito de fraternidade.

\section{Artigo II}

Toda pessoa tem capacidade para gozar os direitos e as liberdades estabelecidos nesta Declaração, sem distinção de qualquer espécie, seja de raça, cor, sexo, língua, religião, opinião política ou de outra natureza, origem nacional ou social, riqueza, nascimento, ou qualquer outra condição (DECLARAÇÃO UNIVERSAL DOS DIREITOS HUMANOS, 1948, p. 01).
A partir dessas assertivas, pressupostos instituídos, há um ideal comum a ser atingido por todos os povos e nações, cujo processo de conscientização, objetiva trazer mais ampla percepção aos indivíduos e a própria sociedade visando assegurar direitos iguais, garantindo assim uma educação mais ampla e capaz de promover o respeito aos Direitos Humanos e liberdade à diversidade. Porém, adotar medidas cabíveis no âmbito nacional e internacional é ainda um desafio para muitos. Toda e qualquer sexualidade(s) estará assegurada na condição de Direitos Humanos fundamentais? A premissa da legitimação de condutas viola e silencia as sexualidades?

\section{Direitos Humanos fundamentais e os desafios da sociedade vigente}

A segunda tentativa de diálogo está na observância da prática global e do principio do Direito Humano Fundamental, quando este se torna responsável pela existência de princípios voltados para a proclamação da cidadania, isso porque há entraves e distanciamentos entre o reconhecimento e o efetivo cumprimento dos direitos. A partir desse entendimento, a declaração não deve ser um mecanismo de mera aplicação conferida a parcelas de sujeitos do Estado, mas de aplicação a todos que estão sujeitos às leis nacionais, significando que o Estado tem obrigações perante os sujeitos não só pela observância de leis que garantam a aplicação plena dos Direitos Humanos, mas pela garantia de sua aplicabilidade. Estevão (2013) mostra que:

estamos num mundo de desigualdades, de microdesigualdades e de interpenetração de múltiplas estruturas de injustiça. Com efeito, mercê das transformações atrás enunciadas, o tempo actual apresenta-se em muitos países como um tempo de grande vulnerabilidade social, em que noções como precariedade e desemprego, emprego temporário, diferenciação, debilidade do movimento social, individualização das relações sociais, desigualdades, insegurança, incerteza, desregulação, fragilidade dos laços comunitários, feminização da pobreza, desqualificação e atomização social demarcam um campo semântico claro de inquietações profundas, apontando para múlti- 
plas formas como muitos são atingidos por um trabalho de verdadeira decomposição, de dessocialização que os vulnerabiliza como seres humanos detentores de direitos e que, objectivamente, enfraquece a substância das nossas democracias (ESTEVÃO, 2013:28-29).

O autor alerta aos desafios, riscos e problemas que avassalam as vidas e mentes das pessoas em tempo de grande vulnerabilidade, mostrando que o tempo presente vem sendo marcado por uma série de barbáries, ressaltando a crise global, a falência do modelo atual das Democracias existentes, fazendo um convite à construção de uma Democracia Global Humanitária, - um compromisso dos governos e da governança mundial com a garantia institucional dos Direitos Fundamentais relacionados à liberdade, segurança, equidade/justiça, direitos civis e políticos.

E na tentativa de conceituar e compreender os Direitos Humanos, emerge uma linha tênue de pensamento, ou seja, o olhar e entendimento sobre a Democracia no Brasil, definindo-a como complexa, em virtude de ser interpretada a partir de diversas abordagens, no entanto, Goodhart (2005, p.150 apud ESTÊVÃO, 2013, p.12) fala do compromisso político que se deve ter para a emancipação universal, assegurando de forma igualitária a todos os cidadãos com fruição dos Direitos Humanos fundamentais. Assim, uma verdadeira Democracia caminha com os Direitos Humanos, bem como ajuda nos processos de construção da emancipação humana e da universalidade deles. Todavia, falta interdialogação, dialeticidade, aceitando mais o caráter conflitual e/ou político da questão, assegurando a visão linear da identidade de gênero. Por fim, elimina qualquer dimensão inclusiva e reforça posturas conservadoras.

No entanto, o projeto de Democracia deve caminhar para a garantia dos Direitos Humanos, mostrando que a Família e a Escola são convocadas a dar seus contributos, saindo das amarras de um sistema normativo e intolerante com as diversidades. Ora, fomentar a emancipação humana ainda é uma alternativa para difundir o ideário democrático, os currículos escolares, rompendo padrões normativos e penetrando no tecido social que se instaura na sociedade contemporânea, - desafios constantes.
Neste caso, a escola deverá assumir-se também pela sua relevância social, cultural e política, como uma organização eminentemente democrática nos seus princípios norteadores, quer ao nível dos seus processos e dinâmicas, quer, obviamente, ao nível das práticas que ocorrem no seu seio (ESTÊVÃO, 2013, p.31).

Pode-se ter na escola a opção por escolhas em que os seus/suas educandos (as) se constituam enquanto cidadãos de direitos, tendo a sua cidadania reconhecida, estimulada que desenvolva o empoderamento de identidades de gênero, através do exercício de direitos, ou seja, com uma educação mais comprometida com a cidadania reconhecida e legitimada. Isso foi visto em entrevistas durante a pesquisa realizada: "sou muitas vezes ridicularizado pelos colegas de escola e na própria família" (depoente zero). A fala mostra a dimensão ético-política, o autoritarismo e as práticas de exclusão. Ainda fala: "a escola e a família trazem marcas em que os sujeitos crescem e aprendem a ser preconceituosas e isso eu senti durante anos nas escolas em que passei".

As falas mostram que essas práticas excludentes estão presentes, desenvolvem e transmitem marcas que interferem nas identidades dos sujeitos. A orientação sexual normativa é sempre vista a partir do ideário de amor binário, podendo ser condição de não se pensar em outras possibilidades, o que resulta em violação dos Direitos Humanos, pois a normatização de pensamentos, posturas, nem sempre são norteadoras do direito à escolha ao modo de vida e opção sexual (ESTÊVÃO, 2011, p. 17). Eis o desafio à escola e da família, eis o desafio à humanidade: assegurar os direitos ou reforçar antigas posturas?

Torna-se essencial repensar a família e seus rearranjos, a escola atual e seus currículos e as novas demandas da sociedade, em especial da família que tem se transformado na sociedade contemporânea. Há de se pensar: esses modelos dão conta de atender as atuais demandas da sociedade e da própria família? Qual o papel da escola nesse processo de mudança? Santos (2001, p 15) ressalta "a esmagadora maioria da população mundial sofre a exclusão, a desigualdade, a polarização entre ricos e pobres". Os Direitos Humanos têm sido um mero discurso, uma quimera e este distanciamento é alimentado pela 
ausência do estado de direito, pela violação dos mesmos e pela multifacetada materialização da(s) violência(s), que está na sociedade, na família e na escola - instituições constitutivas na formação das identidades.

Contrapondo-se aos fundamentos dos Direitos Humanos, as diversas formas de violência que se estabelecem como operadoras das formas de preconceito, demonstram que as violências físicas e simbólicas estão arraigadas em costumes conservadores, em culturas e modos de educação que são interiorizadas e externadas por agentes responsáveis em preservar a ordem pública, em normatizar comportamentos da sociedade civil (ADORNO; PINHEIRO, 1993). Pensando a questão no modelo educacional brasileiro, o processo de reconstrução da escola democrática não tem assegurado às identidades sexuais, recrudescendo a(s) violência(s) e os conflitos sociais e identitários dos mais diversos. E tendo adquirido foro de questão pública que vem ganhando maior visibilidade, multiplicam-se as denúncias de abusos cometidos contra populações desguarnecidas da proteção legal.

A falsa pacificação da violência espelhou-se em um número apreciável de situações e acontecimentos que se acumularam no tempo: assassinatos no campo (6); mortes praticadas ou encomendadas por esquadrões e justiceiros (7); linchamentos (8); maus tratos e torturas impingidos a presos nas delegacias de polícia civil (9) e nas prisões, que não raro resultam em mortes e mutilações, sobretudo por ocasião de motins e rebeliões (10); violências físicas e sexuais de toda a espécie que tem por alvo preferencial mulheres, abusos na parte das vezes cometidos por esposos, companheiros, parentes próximos ou conhecidos (11)... do mesmo modo, haveria que se contabilizar as situações de discriminação, marginalização e violência a que se encontram sujeitos os negros e as populações indígenas (13) (ADORNO, PINHEIRO, 1993, 107-108)

Esses números mostram que ainda não constam os reais dados na sociedade brasileira e a violência, sendo amplamente mostrada, seria um constrangimento. E acrescenta que $\mathrm{a}(\mathrm{s})$ violência(s) e discriminações impostas às pessoas estão geralmente voltadas para o estabelecimento de padrão de comportamento(s) e identidade(s) heteronormativa(s). Assim, sexualidade e identidade de gênero devem se enquadrar dentro dos moldes da heteronormatividade, sendo esta a única orientação sexual considerada "normal". A grande questão em torno dessa palavra é a limitação que ela impõe às lésbicas, pansexuais, gays, transgêneros / andróginos(as) /queer, bissexuais, transexuais (homem, mulher), travestis, crossdressers, drag queen/kings, transformistas ${ }^{2}$, dentre outras múltiplas formas de vivenciar as suas identidades de gênero e/ou sexualidade. E viver abertamente a homossexualidade não é uma tarefa fácil, sobretudo numa sociedade tão heteronormativa quanto a nossa.

Atrelada ao quadro de violações dos Direitos Humanos e retroalimentando-o, a letargia do poder judiciário e das políticas públicas tem sido focalizada, embora vista como característica marcante das instituições que, embora sejam capazes de garantir os direitos para a população, caminham a lentos passos (ADORNO, PINHEIRO, 1993). A promoção dos Direitos Humanos incide em levar em conta o enfretamento desses problemas econômicos, culturais, políticos, educacionais e sociais para alcance da cidadania plena, apesar de ser uma tarefa extremamente árdua e com percalços dos mais variados e violentos na nossa sociedade.

Todavia, revisitando a concepção de violência, Butler (2013), esta mostra que a violência é um ato de brutalidade e interfere na construção das identidades:

\footnotetext{
A desconstrução da identidade não é a desconstrução da política; ao invés disso, ela estabelece como políticos os próprios termos pelos quais a identidade é articulada. Esse tipo de crítica põe em questão a estrutura fundante em que o feminismo, como política de identidade, vem-se articulando. O paradoxo interno desse fundacionismo é que ele presume, fixa e restringe os próprios sujeitos que espera representar e libertar (BUTLER, 2013,p. 213).
}

Diante de tantas atrocidades e abusos físicos e/ou psíquicos contra os sujeitos, existiria alguma possibilidade de ganho nessa luta em prol da libertação? A autora caracteriza as relações intersubjetivas e sociais definindo-as pela opressão, intimidação e pelo medo ou mesmo terror que perpassa em muitas dessas situações no cotidiano. Mostra que violência social é advinda de um pro- 
cesso ligado ao neoliberalismo vigente, cuja onipresença nos força a pensar a heteronomia do econômico e a forma com a qual as lógicas governam as operações.

\section{A violação de Direitos Humanos relacionada à orientação sexual e identidade de gênero}

A terceira tentativa de diálogo está na observância de que a violação de Direitos Humanos está relacionada à orientação sexual e a identidade de gênero presumidas na questão de serem essas pessoas ligadas ao estabelecimento de um padrão determinante e normativo na sociedade, envolvendo variadas espécies de abusos e discriminações sob forma de violências cometidas contra pessoas por motivos dos mais diversos e isso é notório em escolas e nas famílias. A orientação sexual pode ser compreendida como a identidade atribuída a uma pessoa em função de seu desejo e conduta sexual, seja para com outra pessoa do mesmo gênero (homossexualidade), de gênero diferente (heterossexualidade) ou para pessoas de ambos os gêneros (bissexualidade) (RIOS, 2001, p. 388). Há de se considerar que a discriminação pela falta de entendimento do assunto, traz consigo um forte componente o qual Bourdieu (1989) conceituou como violência simbólica, ou seja, "Todo poder de violência simbólica, isto é, todo poder que chega a impor significações e a impô-las como legítimas, dissimulando as relações de força que estão na base de sua força, acrescenta sua própria força, isto é, propriamente simbólica" (BOURDIEU, 1975, p. 19).

Vale também ressaltar que a violência homofóbica cometida contra pessoa cuja vivência da sexualidade, a orientação e/ou identidade de gênero presumida não se conforma à heteronormatividade. Ou seja, são também recorrentes episódios contra sujeitos que, apesar de se reconhecerem como heterossexuais e/ou cisgênero ${ }^{3}$, tendo a eles atribuídas características que fazem com que os perpetuadores das violências os classifiquem como homossexuais e/ou outras categorizações.

Grande parte das famílias convencionais opera a partir de uma crença de que todos os filhos serão heterossexuais e crescerão seguindo estilos de vida e vivências desse tipo (SANDERS, 1994). De fato, arquivos do Grupo Gay da Bahia trazem inúmeros registros de filhos e filhas que sofreram inúmeras agressões físicas por parte dos pais, quando esses tomaram conhecimento da sua homossexualidade (MOTT, 2003). Tal superposição de vitimizações indica o agravamento da vulnerabilidade de grupos sociais como pobres, negros, mulheres e jovens, cuja discriminação é intensificada quando a essa condição associam-se orientação sexual e identidade de gênero. $E$ nas escolas isso é muito comum, desenvolvendo situações constrangedoras que violam os Direitos Humanos.

Portanto, torna-se necessário criar condições propícias para a emergência de novos paradigmas, novos olhares, em que o fazer social reflita uma alteridade fundamentada no resgate de uma ética comprometida com o processo de inclusão social das minorias. Todavia, na sociedade brasileira precisa pairar um sentimento de indignação que gere denúncias e desbanalize as formas veladas de violência a qualquer segmento social.

\section{Diálogos da violência sobre a sexualidade humana}

Estabelecendo diálogos entre a violência e a sexualidade humana, dois esforços são identificados como fundamentais na obra de Butler (2013): um reza o respeito à violência normativa quando pensa e permite outras violências; o outro mostra que a violência está ligada à normatividade considerada ou não inteligivelmente humana, real ou não real, tudo isso dentro do campo ontológico, sendo exercida pelas normas de gênero. Butler (2007) conta:

Cresci entendendo algo sobre a violência das normas de género: um tio encarcerado por ter um corpo anatomicamente anómalo, privado da família e dos amigos, que passou o resto de seus dias em um 'instituto' nas pradarias do Kansas; primos gays que tiveram que abandonar o lar por sua sexualidade, real ou imaginada; minha própria e tempestuosa declaração pública de homossexualidade aos 16 anos, e o subsequente cenário adulto de trabalhos, amantes e lares perdidos. Todas estas experiências me submeteram a uma forte condena- 
ção que me marcou, mas, afortunadamente, não impediu que seguisse buscando o prazer e insistindo no reconhecimento legitimizador de minha vida sexual. Identificar esta violência foi difícil precisamente porque o gênero era algo que se dava por assentado e que ao mesmo tempo se vigiava terminantemente. Se pressupunha que era uma expressão natural do sexo ou uma constante cultural que nenhuma ação humana era capaz de modificar. Também cheguei a entender algo da violência da vida de exclusão, aquela que não se considera 'vida', aquela cuja encarcerarão conduz à supressão da vida, ou uma sentença de morte suspensa (BUTLER, 2007, p. 23-24)..

Nesse descortinar de sua vida, a autora recorda sua experiência pessoal a fim de desnaturalizar o gênero, desconstruir a violência normativa que pressupõe e produz as formas e estruturas idealizadas para o sexo, bem como também se esforça para eliminar as suposições dominantes sobre a heterossexualidade de que é imposta como natural. A leitura dos estudos da referida autora, inquieta, instiga, desestabiliza, enquanto questiona a heteronormatividade e a trata como uma prática reguladora de sexo/gênero/desejo que não pode ser transformada em um problema de discriminação contra indivíduos autônomos baseado em sua orientação sexual, como o conceito de homofobia pode levar a crer. Rupturas com os mananciais ou/e padrões hegemônicos são precípuos, tais como o da heterossexualidade, uma vez que ao elencarmos que é proibido discriminar um homossexual, automaticamente assim o fazemos porque há um padrão comparativo que possui as melhores condições cotidianas. Neste sentido, Rios (2003) diz que:

As mulheres, os negros e os homossexuais terão direitos desde que se comportem e aceitem todas as visões do mundo, as posturas e as condutas dos homens brancos heterossexuais. Essa é a visão simples do princípio da igualdade, limitado ao princípio da antidiscriminação. Trata-se, evidentemente, de um avanço, mas precisamos ir além e interpretar o princípio da igualdade também como princípio da anti-subjugação, que se relaciona com o da igualdade e o da dignidade da pessoa humana, estabelecendo que se deva conferir igual reconhecimento, igual valor às pessoas, independentemente de sua condição, o que difere totalmente de se eleger um padrão ao qual os dessemelhantes devam ser equiparados (RIOS, 2003, p. 157).

A concepção de heteronormatividade evidencia as normas institucionais, culturais e legais que normatizam a heterossexualidade, centra-se na expectativa/demanda do desejo e da identidade heterossexual, é a norma na cultura/sociedade/política, legitimada e codificada institucionalmente, através da família, escola, religiões e outras organizações sociais, constrói-se a partir de uma enorme variedade de práticas comuns e, em última instância, tudo e todos são julgados pelo prisma hétero.

$A(s)$ violência(s) se materializa $(m)$ no momento em que produz $(\mathrm{em})$ e constrange $(\mathrm{m})$ a inteligibilidade de gênero, estruturando e moldando o lócus social, político e cultural, tanto pelo viés do seu impacto sobre as ideias e crenças, mas, sobretudo, por suas consequências práticas nas instituições, leis e vida cotidiana (casamento, adoção, banheiros etc.) que seguem privilegiando quem mais se assemelha as normas e excluindo pessoas e grupos. O estigmatizar, marginalizar, tornam pessoas silenciosas e invisíveis, sendo responsabilizadas por comportamentos, práticas desviantes do modelo imposto. Assim, "leis que buscam estabelecer as linhas causais ou expressivas de conexão entre sexo biológico, gêneros constituídos culturalmente e a 'expressão' ou 'efeito' de ambos nas manifestações do desejo sexual nas práticas sexuais" (BUTLER, 2007, p. 72).

Neste caso, pode-se afirmar então que a coerência do gênero que se realiza na aparente repetição do mesmo, produz como seu efeito a ilusão de um sujeito ideal, uma performance de sujeito eleito para realizar cargos e funções na sociedade, mas o gênero é performativo, no sentido em que constitui como efeito o sujeito que pretendo expressar. Ora, o arcabouço heteronormativo consiste na identificação estrita entre sexo e gênero apresentando a presunção de que machos tornam-se homens e que fêmeas tornam-se mulheres naturalmente e/ou normalmente, assim, sexo consequentemente e naturalmente torna-se gênero, aqui entendido como uma essência interior determinada biologicamente que se transforma em parte exteriormente. 
Dialogando sobre a violência normativa, não se poderá entendê-la restritamente como um tipo de violência que se torna a norma vigente, porém como a violência das normas. As normas de gênero próprias exercem certa violência sobre os corpos que as violam, pois tanto outorgam a violência física típica e rotineiramente como tal, quanto simultaneamente apagam essa violência de nossa apreensão.

As sexualidades dissidentes, os desviantes são a própria razão de ser da heterossexualidade normativa, seu outro termo constitutivo, os discursos reguladores que formam o sujeito de gênero são os responsáveis pela submissão pelo gênero, "o 'eu' nem precede, nem segue o processo dessa 'criação de um gênero', mas apenas emerge no âmbito e como a matriz das relações de gênero propriamente ditas (BUTLER, 1993, p.7).

$\mathrm{O}$ ato da resistência contra violência normativa segundo a autora tornou-se invisível, cotidiana e submissa, um ato violento no sentido de força exercida de um sujeito contra outro. Como esse processo é marcado pelas relações saber/poder/verdade nas normas de gênero, é inadiável problematizar essas relações de maneira a desconstruir o binarismo essencial que, entre outros efeitos, produz a ideia do ignóbil que aqui designa "precisamente aquelas zonas 'inóspitas e 'inabitáveis' da vida social, que são, não obstante, densamente povoadas por aqueles que não gozam do status de sujeito. Neste sentido, pois, o sujeito é constituído através da força da exclusão e da abjeção" (BUTLER, 2001, p. 155).

Portanto, resigna-se que as nuances da diversidade sexual não perfilam convergindo com os padrões heteronormativos e hegemônicos, ainda estão culturalmente associadas a representações sociais subalternizadas e desqualificadoras. Desta forma, a múltipla existência de ser e viver a sexualidade, frequentemente se inscreve no imaginário coletivo como evidência de desvios, patologias, perversão ou caráter falho. Em decorrência, quando são legitimadas e impenetradas nas relações sociais ocasionam as minorias a vivência de solidão, o isolamento e a segregação social.

Todavia, a ampla liberação de costumes que redesenharam o comportamento sexual nas últimas quatro déca- das, os tabus e inibições pairam sobre as manifestações da sexualidade humana e continuam sendo amplamente disseminados e naturalizados, peculiarmente se tratando das chamadas sexualidades alternativas. A realidade atual dentro de parcelas significativas da sociedade vigente é de exclusão, de negação de reconhecimento de identidades plurais, da sonegação de direitos.

A princípio, na universalização do ensino público, há reivindicações e movimentos pela mudança de posturas e normas na educação no Brasil, no entanto, a trajetória da história da educação do país apresenta padrões normativos. Por consequência, a educação como um direito universal de todas ainda está à mercê de muitas transformações e revisitações à Democracia brasileira.

\begin{abstract}
[...] a exclusão, a segregação, a dominação e o poder hegemônicos - resultantes das relações hierarquizadas e desiguais que caracterizam nossa sociedade e violam os princípios iluministas da modernidade. Esse bicho - papão determina a cor, o sexo, a classe social e a orientação sexual que produzem as práticas e relações vividas na escola e define quem deve ou não permanecer nesse espaço (JOCA, 2011, p.13).
\end{abstract}

Nesta perspectiva, questiona-se: a universalização na educação tem ocorrido? A sociedade brasileira tem negado o direito à educação a uma parcela considerável da população que não é regida pela heteronormatividade? Ora, a escola continua sendo um espaço dissimulador de princípios, valores e atitudes algumas que marcar as desigualdades de gênero, classe, etnia/raça e orientação sexual, ou seja, produtora e reprodutora das diferenças.

A dinâmica institucional da escola centraliza suas ações e posturas no disciplinamento, na padronização de currículos, práticas educativas advindas de modelos familiares e sociais, espaços geográficos e arquitetônicos, bem como a padronização de sujeitos. Desta forma reafirma as relações sexuais hegemônicas deslegitimando as questões de gênero e orientação sexual, indo novamente de encontro ao marco legal dos Direitos Humanos. Vale ressaltar que o surgimento da Aids na década de 80 , entre outros desencadeamentos, aduziu para a educação, como pano de fundo, as questões sobre a sexualidade, 
no entanto a abordagem concentrou-se na perspectiva biológica, higienista e preventiva de doenças sexualmente transmissíveis de tal forma que foram abdicados ou ignorados os desejos, prazeres e subjetividades enredados na vivência plena das diversas possibilidades e nuances das sexualidades.

Continuando o diálogo, pensa-se na restrição aos Direitos Humanos percebida na restrição e negação ao direito a uma sexualidade que desvie da norma heterossexual, as formas alternativas de sexualidade que estão submetidas a discursos patologizantes, encontrados com frequência nos discursos institucionais da escola como também entre os/as que estão envolvidos/envolvidas diretamente e indiretamente em seus contextos, visto que tanto a formação inicial e continuada de seus/suas professores/professoras quanto o currículo escolar e os livros didáticos silenciam as temáticas que envolvem a diversidade sexual. Em virtude da omissão e negação da diversidade humana, tem-se como consequência a legitimação da hegemonia heteronormativa e essencialista da sexualidade, conforme cita Joca (2011, p.13) "afirmando a escola enquanto não lugar para as pessoas LGBT ${ }^{4}$."

A escola é um espaço privilegiado por sua missão educativa, civilizatória e ética, influenciando de forma incisiva e benéfica no processo de conscientização ao respeito ao próximo e do fim dos atos de homofobia. Unidades educacionais, a exemplo das creches, as escolas de Educação Básica, Ensino Fundamental, Médio, Profissionalizante, até as Instituições de Ensino Superior, têm sido em muitas situações, tradicionalmente locais onde as pessoas não podem sequer manifestar a sua sexualidade e onde os fatores que ensejam o preconceito, a discriminação e a exclusão não são enfrentados, pelo contrário, em inúmeras situações são silenciadas/silenciados, invisibilizadas/invisibilizados.

Uma sociedade alicerçada pela Democracia em consonância com os Direitos Humanos pressupõe uma educação inclusiva que contemple todos os seguimentos sociais, em específico aos excluídos, uma educação que tenha como política permanente o enfrentamento a qualquer forma de discriminação. Além disso, por uma educação de todos e todas, torna-se imprescindível uma política educacional para uma educação sexual que conceba a sexualidade humana tendo como sustentáculo moral a luta contra a homofobia e o sexismo, pois ambos os processos excludentes violam a constituição, a laicidade do Estado brasileiro e por isso constituem-se significativamente enquanto obstáculos a serem superados.

Unidades educacionais, a exemplo das creches, as escolas de Educação Básica, Ensino Fundamental, Médio, Profissionalizante, até as Instituições de Ensino Superior em Jequié/BA, lócus de nossas pesquisas, têm registrado acontecimentos de violação dos direitos fundamentais a cidadania reconhecida, haja vista que as pessoas não podem sequer manifestar sua sexualidade, havendo preconceitos, discriminações e a exclusões silenciadas. São situações invisibilizadas pelas redes de poder socialmente estabelecidas e que acabam por reforçar estereótipos aviltantes.

Há uma cultura midiática hegemônica colaborando com a solidificação de modelos e conceitos sexistas e lesbo-homo-bi-transfóbicos ${ }^{5}$ que impõe às mulheres, à população negra e aos/as devotos/devotas de religiões não cristãs e especificamente às de matrizes africanas, lésbicas, gays, bissexuais, travestis e transexuais limitações na livre expressão de suas identidades e crenças, constituindo, portanto, flagrante violação da dignidade humana dessas pessoas e dos grupos sociais por elas constituídos. Sobretudo, percebe-se que quando uma pessoa não atende ao ideário masculino ou feminino da cultura vigente logo as esferas sociais nos quais estão inseridos apresentam dificuldades com a questão, neste sentido poderão ocorrer condições propícias de florescimento do preconceito, que por sua vez engendra atitudes e atos de discriminação, reforçando o estigma social associado às práticas sexuais não alinhadas ao padrão hegemônico.

Neste contexto, há necessidade de recorrer-se a educação, pelo viés de rejeição mais decidida a qualquer forma de discriminação, é sendo lícito afirmar que a existência de práticas preconceituosas ofende à própria condição humana e fere os mais altos ideais da democracia forjados na luta e conquistada a duras penas. Desta forma, a eliminação de atitudes, comportamentos e/ou práticas discriminatórias de raça, classe, gênero e identidade de 
gênero, orientação sexual, orientação religiosa ou de qualquer outro tipo de preconceito precisa alcançar patamares mais elevados de construção equitativa da formação humana crítica, finalidade maior da Educação.

\section{Tecendo algumas considerações}

A inexistência de acolhimento e de atitude respeitosa, de aceitação do modo de ser do indivíduo, acaba agudizando problemas de ajustamento da identidade e autoestima visto que potencializa os danos causados pela discriminação social sofrida em espaços sociais, especialmente na família e na escola. Assim, a temática acerca das sexualidades não heterossexuais necessita ser repensada e questionada, a fim de se tornar visível numa sociedade cuja violação dos Direitos Humanos deixa a desejar, estando relacionada à orientação sexual e identidade de gênero. Nesta perspectiva, ainda há muito a ser feito para promover o respeito à diversidade sexual para a conquista de uma sociedade mais justa e solidária, garantindo assim a cidadania.

Ao entrevistar familiares de jovens, professores e alunos das escolas públicas de Jequié/BA, observou-se nas vozes dos sujeitos que há forte expectativa de conquista de direito fundamental, - o que mostra a necessidade de definição de políticas educacionais que orientem propostas de formação inicial e continuada de professores para orientação sexual, bem como orientar e esclarecer famílias na questão da identidade de gênero, ou seja, como os sujeitos se identificam. Nessa perspectiva, a escola necessita estar bem mais ciente de seu papel e a família deve assumir o compromisso de, em parceria com a sociedade civil e instituições, contribuindo com a construção de um novo olhar, respeitar diversidade. Mas isso só será possível quando efetivamente houver comprometimento não apenas dos poderes públicos legitimamente constituídos, mas também da sociedade civil no sentido de transformá-la em potencial de cidadania.

Todavia, a construção de diálogos será mais bem materializada na medida em que a compreensão da importância e do significado de uma educação transformadora esteja presente no cotidiano das pessoas, na sociedade na qual a exclusão, o preconceito, a discriminação e a negação de direitos aos diferentes implicam na abertura de espaços para a construção de políticas públicas voltadas para a valoração das diferenças. Reconhecidamente, a sociedade brasileira só poderá ser considerada justa, igualitária e democrática se combater efetivamente todas as formas de preconceito e discriminação existentes em seu meio e segmentos e a escola é um canal que possibilita discussões. A família, sendo constitutiva, é porta aberta para novas compreensões.

E para que se estabeleça a dignidade plena da pessoa, recorre-se a Santos $(2001$, p. 23) quando sinaliza que em relação à sexualidade, torna-se necessário investigar se as violências empreendidas às minorias sexuais, sendo que são naturalizadas e influenciadas através das instituições como: Família, Escola, Igreja dentre outras que nem sempre enveredam pela emancipação humana, ferindo o princípio da liberdade e o princípio da diferença. E apesar de uma sociedade considerar acentuadas as desigualdades, só o desejo da igualdade não basta. Haverá sempre um grande esforço no intuito de superar inúmeros obstáculos e estigmas que a sociedade historicamente incorpora. Portanto, além das reflexões acerca dos Direitos Humanos, Educação e Diversidade Sexual, é necessário criar condições propícias para a emergência de novos paradigmas, outros olhares, onde o fazer social reflita a alteridade fundamentada no resgate de uma ética comprometida com o processo de inclusão social das minorias.

É mister fomentar na sociedade brasileira um sentimento de indignação que gere a denúncia e desbanalize as formas veladas de violência a qualquer segmento social. Considera-se aqui a importância da construção coletiva de um projeto de educação que atenda aos Direitos Humanos, tornando possíveis diálogos entre a identidade sexual e a de gênero, criando agendas, ações e políticas públicas promotoras de uma cultura de paz, respeito e valorização à diversidade humana. 


\section{Notas}

1 Declaração Universal dos Direitos Humanos, adotada e proclamada pela resolução 217 A (III) da Assembleia Geral das Nações Unidas em 10 de dezembro de 1948. Disponível em 08 de novembro de 2013: http://www.brasil.gov.br/cidadania-e-justica/2009/11/declaracao-universal-dos-direitos-humanos

2 Cf extraída da obra de JESUS (2012), as nomenclaturas das identidades sexuais foram inscritas partindo do entendimento que escrever ou falar conforme um vocabulário reconhecido pelas pessoas representadas é essencial para valorizar a cidadania, os vocábulos foram consultados pela referência que segue considerados como termos inclusivos, por representarem adequadamente o cotidiano de homens e mulheres transexuais, de travestis e outras pessoas transgêneras, buscando-se representar minimamente, e com didática, a sua diversidade identitária, incluindo conceitos relacionados a gênero e orientação sexual.

3 Cf extraída de Jesus (2012), cisgênero é "um conceito que abarca as pessoas que se identificam com o género que lhes foi determinado quando de seu nascimento, ou seja, as pessoas não-transgênero". A origem da palavra vem do Latim, onde o prefixo cis- significa "ao lado de" ou "no mesmo lado de", fazendo alusão à identificação, à concordância da identidade de género da pessoa com seu sexo (sexo biológico, sua genitália).

4 LGBT, ou ainda LGBTTT, é a sigla de Lésbicas, Gays, Bissexuais, Travestis, Transexuais e Transgêneros. Embora refira apenas seis, é utilizado para identificar todas as orientações sexuais minoritárias e manifestações de identidades de género divergentes do sexo designado no nascimento.

50 termo utilizado de acordo ao Dicionário de Preconceitos da Liga Humanista afirma que Lesbo/Homo/Bi/Transfobia (lesbo/homo/bi/transfóbico) é o preconceito contra LGBTT (Lésbicas, Gays, Bissexuais, Transexuais, Travestis e demais minorias de orientação sexual ou identidade de gênero). Muitas vezes "homofobia" é usado como guarda-chuva para todas as versões de preconceito contra orientações sexuais minoritárias. Disponível em: http://www.ligahumanista.org.br/p/dicionario-de-preconceitos.html. Acesso em 15 de dezembro de 2013.

\section{Referências}

ADORNO, Sergio e PINHEIRO, Paulo Sérgio. Violência contra crianças e adolescentes, violência social e Estado de Direito. SP: São Paulo em Perspectiva. Fundação Seade, v.7, n.1, jan./ mar. 1993.

BOURDIEU, P.; PASSERON, J.C. A reprodução: Elementos para uma teoria do sistema de ensino. Rio de Janeiro: Francisco Alves, 1975.
BUTLER, Judith. Problemas de gênero: feminismo e subversão da identidade. Trad. Renato Aguiar. $5^{\circ}$ ed. Rio de Janeiro: Civilização Brasileira, 2013.

.El género en disputa. El feminismo y la subversión de la identidad. Barcelona: Paidós, 2007/ 1990/1999.

Corpos que pesam: sobre os limites discursivos do "sexo". In: LOURO, Guacira Lopes (Org). O Corpo Educado. Pedagogias da Sexualidade. Belo Horizonte: Autêntica, 2001.

ESTÊVÃO, Carlos Alberto Vilar. Democracia política, democracia escolar e educação para os direitos humanos. Educação. Porto Alegre, Abr 2013, vol.36, no. 01

- Carlos Alberto Vilar. Direitos humanos e educação para uma outra democracia. Revista Ensaio Avaliação e Políticas Públicas em Educação (Online), v.19, n.70, p. 9-20, 2011. Acesso em: 05 de novembro de 2013.

JESUS, Jaqueline Gomes de. Orientações sobre a população transgênero: conceitos e termos. Brasília: Autor, 2012.

JOCA, Alexandre Martins. Direitos humanos e diversidade sexual: pelo direito à educação e à diversidade na escola. In: Educação e diversidade sexual. Rio de Janeiro: MEC, 2011.

MOTT, Luiz. Homossexualidade: Mitos e verdades. Salvador, Ed. GGB, 2033.

RIOS, Roger Raupp; PIOVESAN, Flávia. A discriminação por gênero e por orientação sexual. Série Cadernos do CEJ, vol. 24, 2003. Disponível em: < http: // www. cjf. gov. br /revista /seriecadernos / vol24 / artigo05.pdf >. Acesso em: 15 de novembro de 2013.

SANDERS, G. 0 amor que ousa declarar seu nome: do segredo à revelação nas afiliações de gays e lésbicas. In: E. Imber-Black (Org.), Os segredos na família e na terapia familiar (p. 219- 244). Porto Alegre: Artes Médicas, 1994.

SANTOS, Boaventura de Sousa. Seis razões para pensar. Lua Nova. 2001.

Recebido em: 03/03/2014

Aceito em: 01/04/2014

Publicado em: 30/04/2014 
